\title{
TRAJNOSTNI RAZVOJ OB REKI VIPAVI
}

Spomladi 2015 so predstavniki Alumni kluba geografov Univerze v Ljubljani, Komisije za hidrogeografijo Zveze geografov Slovenije in Občine Miren predstavili »Strokovne zasnove ureditve vodnega in obvodnega prostora ob reki Vipavi na območju občine Miren-Kostanjevica«. Dokument, ki je nastal na podlagi dveh delavnic z domačini ter terenskega druženja geografov, išče nove razvojne priložnosti ob vse bolj čisti Vipavi in nove možnosti za čezmejno sodelovanje. Predlog za nov pristop k razvoju območja je kmalu postal »vsevipavska« zgodba: trajnostni prostorski razvoj se ne načrtuje več izključno na območju posamezne občine, ampak v celotnem porečju Vipave, kar je poseben pri-

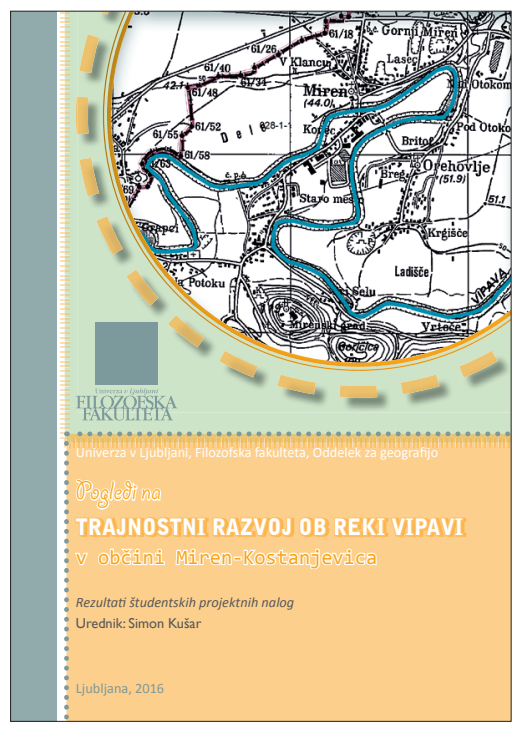
mer v Sloveniji.

Med strateškimi predlogi je bilo zapisano: »Razvojna prizadevanja za izrabo potencialov je potrebno razširiti z vključevanjem študentov različnih strok«. Geografi smo različne vidike trajnostnega prostorskega razvoja ob reki Vipavi vključili v redno pedagoško delo pri seminarjih in vajah tako na prvi kot drugi stopnji študija geografije $\mathrm{v}$ okviru predmetov Regionalni razvoj in regionalna politika, Metode in tehnike v regionalnem planiranju, Ekonomska geografija, Geoinformacijska podpora odločanju, Geoinformacijski modeli in scenariji, Razvojna neskladja na podeželju, Endogeni razvoj podeželja in Pokrajinska ekologija. Pri tem delu je sodelovalo 80 študentov ter 7 učiteljev. Končni rezultat procesa, ki je potekal v študijskem letu 2015/2016, je 12 različnih raziskovalnih nalog, veliko samostojnega dela, zbiranja virov in literature, obiskov na terenu in pogovorov z domačini, a se kljub mozaičnosti med seboj povezujejo v prizadevanjih za trajnostni prostorski razvoj ob reki Vipavi.

V sodelovanju $z$ domačini so tako študentje poskušali odgovoriti na številna praktična vprašanja, povezana s trajnostnim prostorskim razvojem ob Vipavi. Kako izboljšali poplavno varnost? Katera območja ob reki Vipavi so primerna za razvoj rekreacije na vodi in ob vodi? Kje naj se trasirajo nove kolesarske poti? Kako vključiti zgodovinsko dediščino v razvoj novih turističnih produktov? Kako povezati lokalne proizvajalce in ponudnike različnih storitev? Kakšen pogled na razvoj ob reki Vipavi imajo domačini? Zanimalo nas je torej, kako upravljati s prostorom in upoštevati geografske prednosti in omejitve te slovenske pokrajine, pri čemer je $\mathrm{v}$ razvojnih pobudah vselej prisotna komponenta trajnostnega razvoja.

Pomemben del spoznavanja prostora in njegovega potenciala je bilo razumevanje pogleda domačinov na prihodnji razvoj ob reki Vipavi. S pomočjo odgovorov 161 anket se je izkazalo, da domačini kot največjo težavo v prostoru prepoznajo poplavljanje reke 
Vipave, za razvoj območja pa kot pomembno prepoznajo trajnostno prometno infrastrukturo, kot so pešpoti in kolesarske steze ter izboljšanje javnega potniškega prometa.

Tako so študentje želeli prispevati k reševanju poplavne ogroženosti Mirna. Na podlagi izbranih kriterijev so preučili možnost za izgradnjo prekopa oziroma podzemnega kanala, ki bi del poplavnega toka reke Vipave preusmeril skozi Miren in tako zmanjšal škodo, ki jo v naselju povzročajo poplave. Kot najustreznejša rezultata analize so ovrednotili dve možnosti poteka kanala, severno in južno pot. Severna pot je krajša, a se obenem nekoliko bolj približa stavbam (do štiri metre), južna pot pa je občutno daljša, vendar je od obstoječih zgradb oddaljena vsaj deset metrov.

Glede dostopnosti in urejenosti reke Vipave v občini Miren Kostanjevica že nekaj časa velja, da reka z izgradnjo čistilnih naprav v celotnem porečju pridobiva na športnem, rekreacijskem in turističnem pomenu. Študenti so se v eni od raziskovalnih nalog lotili analize reke Vipave in njenega obrečnega pasu z vidika dostopnosti in urejenosti ter podali svoj pogled na potenciale in izzive za razvoj turistične in športnorekreacijske infrastrukture ob reki Vipavi.

Ključni rezultat je tematska karta, na kateri so prikazani naslednji elementi: dostopnost do struge, preoblikovanost struge, cestna dostopnost ter infrastruktura ob sami reki Vipavi. Poleg teh elementov pa so na karti označili še območja, katera so se jim po opravljeni analizi zdela najbolj primerna za razvoj turizma in športno-rekreativnih dejavnosti.

V modeliranju erozije prsti so študentje ugotovili, da večina površin občine ni ogrožena predvsem zaradi obširnih uravnanih delov površja, relativno majhnih naklonov in gozdnatosti. Z zmerno intenziteto se sooča 15 \% površine občine; z močno, zelo močno ali ekstremno močno erozijo pa le 2,6 \% površine občine. Moč erozije se občutno poveča ob odstranitvi rastlinske odeje, pri zbitosti prsti ali globokem oranju. Med manj ogrožene dele spada celotni ravninski del občine, z izjemo sadovnjakov, vinogradov in travnikov na Biljenskih gričih in na prehodu na kraško planoto.

Kot izziv na področju turistične infrastrukture so si študentje izbrali umeščanje kolesarskih poti s turistično namembnostjo. Na podlagi geoinformacijske podpore odločanju in večkriterijskega vrednotenja s pomočjo relevantnih kriterijev so poskušali ovrednotiti primernost območja Vipavske doline in njenega zaledja za umeščanje tras kolesarskih poti s turistično namembnostjo ter določiti najustreznejše trase, primerne za prostorsko umestitev novih kolesarskih poti. Osnovni cilj je bil zagotoviti trase kolesarskih poti, ki bi bile ustrezne $\mathrm{z}$ vidika prometne varnosti, katere bi v čim večji meri potekale po obstoječi, z motornim prometom manj obremenjeni cestni infrastrukturi, primerni za kolesarjenje. Le-te bi se čim bolj približale vodnim površinam oziroma turistično zanimivim lokacijam ter obstoječi gostinski in prenočitveni turistični ponudbi območja, hkrati pa naj bi bile trase načrtovane tudi z upoštevanjem varstvenih vidikov (zlasti varstva kakovostnih kmetijskih zemljišč ter varstva varovanih in zavarovanih območij narave in kulturne dediščine). Zasnovali so pet kolesarskih tras, ki glede na uporabljeno metodologijo in kriterije potekajo po najbolj optimalnih lokacijah za umeščanje kolesarskih poti, in sicer od Mirna do Vipave, od Mirna do Štanjela, od Štanjela do Vipave, od Mirna do Ajševice ter od Ajševice do Potoč.

Po večkratnih obiskih občine Miren-Kostanjevica, natančnem opazovanju, raziskovanju ter pogovoru s številnimi domačini, so študenti zaznali določene težave, s katerimi 
se tamkajšnji prebivalci soočajo. Kot bistven problem občine Miren-Kostanjevica lahko izpostavimo njeno nepovezanost, kar se odraža na dveh ravneh. Občina se deli po naravnogeografskih značilnostih na dolinski flišni in vzpeti kraški del, med katerima močno primanjkuje sodelovanja. Na drugi strani ni povezanosti tudi med podjetniki, saj jih večina deluje individualno. Že sama občina ima obrobno geografsko lego. Kot obroben lahko označimo predvsem kraški del, ki ima precej slabe povezave z dolino in širšo okolico. Sooča se z odseljevanjem mladih, njegovi prebivalci pa se večkrat počutijo »odrezani od sveta«. Problematiko so prepoznali tudi v nerabi bogatih potencialov, kot so lokacija, okoljske danosti, reka, obmejnost in turizem, ki bi občini lahko predstavljali dodano vrednost.

Najpomembnejši potencial so prepoznali v povezovanju in sodelovanju znotraj lokalne skupnosti. Ugotovili so, da bi sodelovanje lahko potekalo na več ravneh (med podjetniki, kmetovalci, lokalnimi prebivalci, ustanovami) in med različnimi generacijami (vrtčevski otroci, šolarji, starostniki, delovno aktivno prebivalstvo), glede na obmejno lego občine pa tudi na meddržavni ravni. V okviru tega povezovanja obstaja tudi potencial za razvoj alternativnih oblik podjetništva - na primer za vzpostavitev podjetja, ki ga vodi lokalna skupnost. Pomemben potencial so prepoznali tudi v rabi drugih lokalnih virov: bližine reke, privlačnega naravnega okolja, razgibanega reliefa, zgodovine, bogate naravne in kulturne dediščine, dolge tradicije sadjarstva in vinogradništva ter kulinarike.

Nadalje so študenti predlagali, da znotraj podjetja, ki ga upravlja lokalna skupnost, ustanovijo lokalno blagovno znamko RIMiren, ki bi povezala lokalno ponudbo, znanje in ideje prebivalcev občine in zaledja ter hkrati dala rimski dediščini novo komponento. Z novo znamko RIMiren želijo v ospredje postaviti tematsko gostinsko ponudbo, ki bo vključevala predvsem izdelke lokalnih ponudnikov. Ta ponudba bi prišla do izraza v dveh dogodkih, ki bi se lahko odvijala v občini. Prvi bi potekal v spomladanskem času in bi bil vezan na otvoritev sezone ribolova v začetku aprila (glavna tema ribe). Konec novembra bi na vrsto prišel drugi del rimskih dni, ki bi tematsko temeljil na vinu.

Raziskovanje razvojnih možnosti in endogenih potencialov občine Miren-Kostanjevica je pokazalo vso paleto možnosti trajnostnega razvoja, a nakazalo tudi pomanjkljivosti, ki so krive, da del teh potencialov ni bil izkoriščen že prej. Z vključevanjem študentov v konkretne projekte na lokalni ravni pa smo na Oddelku za geografijo Filozofske fakultete Univerze v Ljubljani nadaljevali s prizadevanji povezovanja študijskih dejavnosti s prakso, ki jih poskušamo vpeljati v kar največji možni meri in tako dati geografiji aplikativno vrednost, kar mladim geografom bistveno poveča konkurenčnost na trgu delovne sile.

\section{Matej Ogrin}

